\title{
Two-Year Primary Patency Rates After Aortoiliac Occlusive Disease Endovascular Treatment
}

\author{
Mohammad Hassani, ${ }^{1}$ Mohammad Reza Zafarghandi,, ${ }^{2,}$ Morteza Taghavi, ${ }^{2}$ Javad Salimi, ${ }^{2}$ Majid \\ Moini, ${ }^{2}$ Amirsina Sharifi, ${ }^{2}$ Morteza Noaparast, ${ }^{2}$ Mohammad Reza Toubaei, ${ }^{2}$ Morteza Shahbandari, ${ }^{3}$ \\ Somayeh Alsadat Naserinia, ${ }^{4}$ Soheil Saadat, ${ }^{2}$ and Farzad Biniaz ${ }^{5}$ \\ ${ }^{1}$ Department of Surgery, Taleghani Hospital, Shahid Beheshti University of Medical Sciences, Tehran, Iran \\ ${ }^{2}$ Sina Trauma and Surgery Research Center, Sina Hospital, Tehran University of Medical Sciences, Tehran, Iran \\ ${ }^{3}$ Isfahan University of Medical Sciences, Isfahan, Iran \\ ${ }^{4}$ Ethics Group of Tehran University of Medical Sciences, Tehran, Iran \\ ${ }_{5}^{5}$ Department of Radiology, Sina Hospital, Tehran University of Medical Sciences, Tehran, Iran \\ "Corresponding author: Mohammad Reza Zafarghandi, Sina Trauma and Surgery Research Center, Sina Hospital, Hasan Abad Sq, Tehran University of Medical Sciences, Tehran, \\ Iran. E-mail: zafarghandi@tums.ac.ir
}

Received 2017 July 16; Revised 2017 December 06; Accepted 2018 March 12.

\begin{abstract}
Background: In the last decade, great attention has been paid to endovascular treatment and now it is considered as a treatment of choice in aortoiliac occlusive disease.

Objectives: To report our 2-year follow-up experience in this field.

Patients and Methods: A retrospective review was conducted on patients who underwent aortoiliac angioplasty with or without stenting from September 2013 to March 2015. Medical profile, clinical signs and symptoms, and technical variables of angioplasty were recorded. Technical success rate and primary patency rate were the main outcome measures.

Results: Fifty eight patients ( $\mathrm{m}: \mathrm{f}=53: 5)$ with the mean age of $64.28 \pm 10.88$ years and the most common initial presentation of intermittent claudication (37.9\%) were evaluated. The technical success rate was $100 \%$ in each transatlantic inter-society consensus (TASC) subtypes. The mean time of hospital stay was $9.45 \pm 7.96$ days. The mean follow up period was $14.01 \pm 5.87$ months (6-27months). The Kaplan-Meier analysis estimated a primary patency rate of TASC subtypes A-D at 1 year as $96.3 \%, 100 \%, 66.7 \%$, and $96.3 \%$, respectively. Two years primary patency rates were $96.3 \%, 100 \%, 66.7 \%$, and $81.6 \%$ for A-D TASC subtypes, respectively. There was no complication or death in the study group.

Conclusion: Endovascular treatment for different TASC II subtypes is associated with considerable technical success rate and primary patency rate even in TASC D, which has been previously indicated to be treated with open surgical procedures.
\end{abstract}

Keywords: Endovascular Therapy, TASC II Morphological Stratification, Aortoiliac Occlusive Disease, Technical Success Rate, Primary Patency Rate

\section{Background}

During the last two decades, technical advances have changed aortoiliac occlusive disease management in both diagnosis and treatment (1). Computed tomographic angiography has pretermitted digital subtraction angiography in imaging (2) and endovascular therapy has become the treatment of choice for debilitating aortoiliac occlusive disease in patients complaining of lower limb claudication (3). This growing interest for percutaneous transluminal angioplasty is based on its safety, technical feasibility (4), and non-invasive nature compared with open surgery along with lower mortality and infection rates (5). The trans-atlantic inter-society consensus (TASC) mor- phological stratification (6) is widely used to categorize peripheral arterial disease lesions. This categorization is based on the extent of vessel occlusion or stenosis including unilateral or bilateral lesions, presence of calcification, and length of vessel occlusion and the overall complexity of atherosclerotic lesions. TASC also proposes treatment options in each group, as it has recommended open surgical management in severe disease (TASC D) and endovascular therapy for less complicated lesions (TASC A, B, and C) (6). Primary studies have reported technical success rate ranging from 80 to $85 \%$ (7-9), but recent studies have shown that a technical success rate of 92 to $95 \%$ (10-12) can be achieved even in type $C$ and $D$ lesions. Thus, we assume 
TASC II morphological stratification is an accurate tool to candidate a patient with aortoiliac occlusive disease for endovascular treatment and this technique is widely applicable in every TASC subtype with a considerable technical success rate and primary patency rate.

\section{Objectives}

In the present study we aim to report our two-year experience of endovascular treatment of aortoiliac disease. We assume this study is the first of its kind in our country.

\section{Patients and Methods}

\subsection{Study Design}

This study was designed as a retrospective observational study. The institutional review board and ethics committee of Tehran University of Medical Sciences have approved the study protocol.

\subsection{Setting}

Medical profiles of all consecutive patients who were treated for peripheral arterial disease by endovascular intervention at Sina hospital from September 2013 to March 2015 were gathered. The following data were recorded in all cases: age, gender, comorbidities, pre-procedure symptoms, previous drug history, smoking habit, technical success rate in endovascular treatment, hospital stay, and post-operative complication. All procedures were performed by the same vascular surgery team with fixed imaging. Plavix (450 mg) was prescribed orally before the procedure. Heparin sodium was administered systematically at 4000 to 8000 IU to achieve the activated clotting time of higher than 250 seconds. After obtaining local anesthesia, arterial access through ipsilateral or contralateral femoral approach through introducer sheaths that ranged in size from 4 - 5 F was made. A 0.035-inch hydrophilic guide wire (Terumo Guidwire, Somerset, New Jersey, US) was used to pass occlusion and stenosis. Standard angioplasty balloons (Sleek OTW, Cordis, Johnson and Johnson, US) matching the length of the lesion and diameter of the artery were used. If after primary angioplasty with pressure ranging from 4 to 16 atm maintaining for 60 to 120 seconds, there was residual stenosis (defined as $\geq 30 \%$ reduction in luminal diameter of treated artery in comparison with adjacent segment) or presence of flow limiting intimal flap, a stent was inserted.

Patients were given aspirin $80 \mathrm{mg} /$ daily/PO, plavix 75 $\mathrm{mg} /$ daily/PO and atorvastatin $40 \mathrm{mg} /$ daily/PO for 2 months. After this period, aspirin, cilostazol or pentoxifyllin and atorvastatin was prescribed for life-time.
The follow up visit was set up at 2 weeks after the procedure, then in every 3 months for the first year then each 6 months for the second year. In every visit, improvement and clinical status, distal pulse to angioplasty site, patient's history and duplex ultrasound examination was assessed. If patients reported recurrent symptoms in history accompanied with recurrent stenosis $>50 \%$ detected by duplex scan, they were a candidate for repeat intervention.

\subsection{Participants}

All patients complaining of intermittent claudication, tissue loss or rest pain were initially visited by the vascular surgeon in the study period. Patients willing to participate were given an informed consent and other ones received standard treatment.

\subsection{Variables:}

Technical success was defined as residual stenosis < $30 \%$ after initial endovascular intervention. Primary patency rate was considered based on society for vascular surgery guidelines (13).

\subsection{Data Measurement}

All patients underwent either computed tomography angiography or digital subtraction angiography in order to clarify stenosis or occlusion in culprit vessel. In addition, all lesions were categorized based on TASC II (6).

\subsection{Bias}

We tried our best to follow all patients treated in our center, but in some cases patients were missed or they died. During the follow up period, nine patients died and 11 patients were missed to follow though we tried several times to contact and invite them for follow up visits. The follow up rate was $75 \%$. Therefore, excluding these patients may have led us to overestimate the primary patency rate.

\subsection{Study Size}

As we aimed to report our 2-years experience in endovascular treatment of aortoiliac occlusive disease, eligible patients during this period were enrolled into the study. 


\subsection{Statistical Methods}

Categorical variables are shown as frequency (\%) and continuous variables are shown as mean (standard deviation). Categorical variables were compared using the chisquared test. An independent student t-test was used to compare means between the two groups. Kaplan-Meier analysis was used to assess survival. If it was not possible to attain information about patient's status at intended time(s), it was considered censored after the last known status time. All analyses were performed by the two-sided method using statistical package of social science software (SPSS version 22; SPSS, Inc., Chicago, IL), and the P value of $<0.05$ was set as statistically significant.

\section{Results}

\subsection{Participants}

A total number of 58 patients with male: female ratio of 53:5 and mean age of $64.28 \pm 10.88$ were assessed for treatment of aortoiliac lesions during study period.

\subsection{Descriptive Data}

The most common comorbidity among the study population was diabetes mellitus affecting 25 patients (43.1\%). Other comorbidities were as follows: hypertension (21 patients, 36.2\%), hyperlipidemia (7 patients, $12.1 \%$ ), and congestive heart failure (10 patients, $17.2 \%)$. Only one person was under routine dialysis and 43 patients (74.1\%) had a history of smoking. Table 1 demonstrates patient comorbidity in different TASC subtypes.

Previous medication histories of all patients were reviewed. Aspirin was used by 31 patients (53.4\%) followed by statins (21 patients, $36.2 \%$ ), clopidogrel (11 patients, $19 \%$ ), $\beta$ blockers ( 5 patients, 8.6\%), and warfarin (3 patients, $5.2 \%$ ).

Peripheral arterial disease was mostly presented with intermittent claudication (37.9\%). Ulcer, tissue loss, and rest pain were other common symptoms $(25.9 \%, 19 \%$, and $17.2 \%$, respectively).

\subsection{Outcome Data}

Based on TASC II morphological stratification, 27, 4, 5, and 22 patients were in group A, B, C, and D, respectively. Intermittent claudication and tissue loss in TASC II subtypes are shown in Table 2.

For the whole study population, the mean percentage of stenosis in aortoiliac lesion was $81.36 \pm 8.41 \%$ preoperatively and it became $11.84 \pm 5.92 \%$ after the procedure $(\mathrm{P}$ value $=0.02$ ). In addition, the mean lesion length was 4.72 $\pm 3.33 \mathrm{~mm}$. Twenty one patients had complete occlusion in aortoiliac lesions. Twenty four patients underwent single procedure and 34 underwent multiple procedures. Angioplasty without stenting was performed in one patient and angioplasty with stenting was performed in 57 patients. In most patients, the number of applied stents was 1 (mode). Self-expandable bare stent was used in 45 (77.6\%) lesions and balloon expandable stent was used in 19 (32.8\%) lesions.

The mean time of hospital stay was $9.45 \pm 7.96$ days. There was no bleeding in the site of procedure and death. Patients were followed up for $14.01 \pm 5.87$ months (6 - 27 months). During the time of follow ups, 54 patients had no signs of stenosis or occlusion in duplex ultrasonography imaging, while one presented with occlusion and three other with stenosis. Twenty four (96\%) of the patients who presented with foot ulcer reported complete wound healing and one (4\%) reported more than $50 \%$ healing (P value $=0.01)$. While $36(81.1 \%)$ patients reported improvement in claudication, eight patients (18.2\%) reported no improvement $(P$ value $=0.04)$.

\subsection{Main Results}

Technical success rate was 100\% in aortoiliac lesions of all TASC II subtypes. For the whole study population, the mean primary patency rate at 6,12 , and 24 months was $92 \%$, $92 \%$, and $88.6 \%$, respectively (P values for all follow ups was $<0.05)$. Primary patency rates of different TASC II subtypes are presented in Table 3 and Figure 1. The Kaplan-Meier analysis estimated primary patency rate of TASC subtypes A - D at 1 year as $96.3 \%, 100 \%, 66.7 \%$, and 96.3\%, respectively (Pvalue $=0.38$ ). Two-year primary patency rates were $96.3 \%$, $100 \%, 66.7 \%$, and $81.6 \%$ for A - D TASC subtypes, respectively $(\mathrm{P}$ value $=0.38)$.

\section{Discussion}

In this study, we reviewed medical profile, endovascular treatment variables and post-operative follow up visits of 58 patients with aortoiliac lesions. Peripheral arterial disease is associated with multiple comorbidities as diabetes, hypertension, hyperlipidemia, ischemic heart disease, and smoking history (3). All of our patients had at least one of these risk factors and the most common one was smoking and diabetes. Humphries et al. (14) reported hypertension and hyperlipidemia as the most common comorbidities while Kudo et al. (15) reported hypertension and smoking as the most prevalent risk factors. Although all these risk factors (except smoking) may be considered as metabolic syndrome components, the difference in prevalence may be attributed to epidemiological variation between study groups of each study.

In our study population, technical success was achieved in $100 \%$ of all TASC subtypes. Previous studies have reported technical success rate to vary between 


\begin{tabular}{|c|c|c|c|c|}
\hline Variables & A & B & $\mathrm{C}$ & D \\
\hline \multicolumn{5}{|l|}{ Sex } \\
\hline Male & $26(96.3)$ & $4(100)$ & $5(100)$ & $18(81.8)$ \\
\hline Female & $1(3.7)$ & $0(0)$ & $0(0)$ & $4(18.2)$ \\
\hline \multicolumn{5}{|l|}{ Smoking } \\
\hline Yes & $22(81.5)$ & $3(75)$ & $4(100)$ & $14(63.6)$ \\
\hline No & $5(18.5)$ & $1(25)$ & $1(20)$ & $8(36.4)$ \\
\hline \multicolumn{5}{|l|}{ HTN } \\
\hline Yes & $10(37)$ & $0(0)$ & $3(60)$ & $8(36.4)$ \\
\hline No & $17(63)$ & $4(100)$ & $2(40)$ & $14(63.6)$ \\
\hline \multicolumn{5}{|l|}{ DM } \\
\hline Yes & $14(51.9)$ & $2(50)$ & $2(40)$ & $7(31.8)$ \\
\hline No & $13(48.1)$ & $2(50)$ & $3(60)$ & $15(68.2)$ \\
\hline \multicolumn{5}{|l|}{ Dialysis } \\
\hline Yes & $27(100)$ & $0(0)$ & $0(0)$ & $1(4.5)$ \\
\hline No & $0(0)$ & $4(100)$ & $5(100)$ & $21(95.5)$ \\
\hline \multicolumn{5}{|l|}{ Claudication } \\
\hline Yes & $13(48.1)$ & $2(50)$ & $2(40)$ & $7(31.8)$ \\
\hline No & $14(51.9)$ & $2(50)$ & $3(60)$ & $15(68.2)$ \\
\hline \multicolumn{5}{|l|}{ Rest pain } \\
\hline Yes & $4(14.8)$ & $1(25)$ & $1(20)$ & $5(22.7)$ \\
\hline No & $23(85.2)$ & $3(75)$ & $4(80)$ & $17(77.3)$ \\
\hline
\end{tabular}

Abbreviations: DM, diabetes mellitus; HTN, hypertension; TASC, transatlantic inter-society consensus.

${ }^{\mathrm{a}}$ Values are expressed as No. (\%).

\begin{tabular}{|c|c|c|}
\hline TASC II & Intermittent claudication & Tissue loss \\
\hline$A(n=26)$ & 13 & 3 \\
\hline B $(\mathbf{n}=\mathbf{4})$ & 2 & 1 \\
\hline$C(n=4)$ & 2 & 0 \\
\hline $\mathbf{D}(\mathbf{n}=\mathbf{2 0})$ & 7 & 4 \\
\hline
\end{tabular}

Abbreviation: TASC, transatlantic inter-society consensus

TASC II subtypes, as TASC A (91.6 - 96.9\%) has higher and TASC D has lower rates $(71.4-91.6 \%)(3,16,17)$. On the hand, Tewksbury et al. (18), and Taurino et al. (19) reported $100 \%$ technical success even in TASC D subtype. Given this technical success rates, the accuracy of TASC criteria to choose between therapeutic options would be confirmed. The difference between reported technical success rates may be due to specialist experience and patient's profile. Although these factors may be contributed to the difference seen, it is needed to be approved by controlled studies.

\begin{tabular}{lccc}
\hline Table 3. Primary Patency Rate of TASC Subtype at Different Follow Ups $^{\mathrm{a}}$ \\
\hline TASC Subtypes & \multicolumn{4}{c}{ Primary patency rate, months } \\
\cline { 2 - 4 } & $\mathbf{6}$ & $\mathbf{1 2}$ & $\mathbf{2 4}$ \\
\hline TASC A & 96.3 & 96.3 & 96.3 \\
TASC B & 100 & 100 & 100 \\
TASC C & 100 & 66.7 & 66.7 \\
TASC D & 96.3 & 96.3 & 81.6 \\
\hline
\end{tabular}

Abbreviation: TASC, transatlantic inter-society consensus

${ }^{\mathrm{a}}$ Values are expressed as percentage.

Post angioplasty complication can be divided into major and minor ones. Major group includes complication including acute iliac artery thrombosis, arterial rupture, acute dissection, stent infection, distal embolization, and renal failure. Minor complications are groin hematoma and whatever requires no treatment. In the present study, we had no cases of either minor or major complications; therefore, we are unable to make any comparison between 


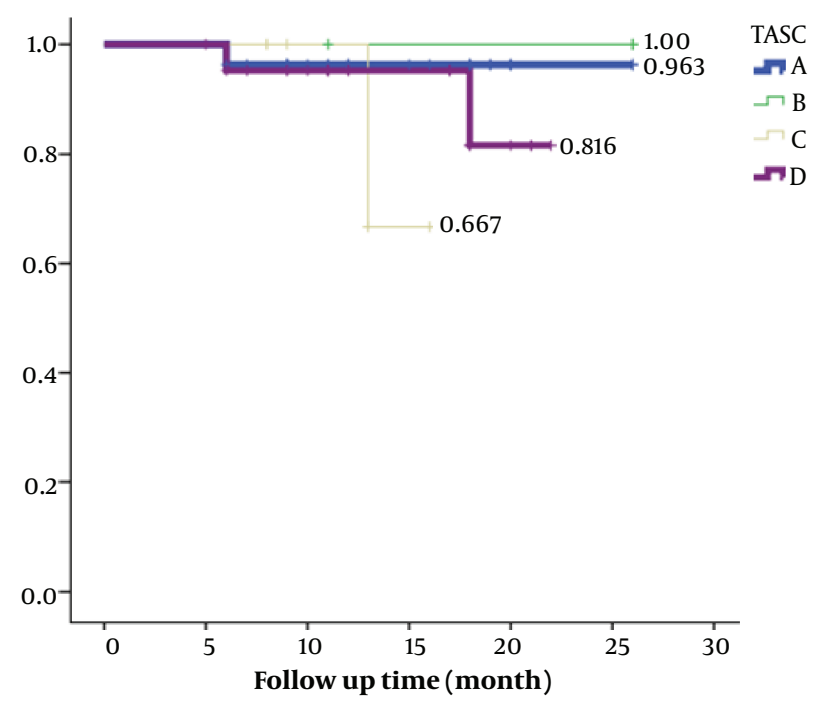

Figure 1. Primary patency rate of transatlantic inter-society consensus (TASC) subtypes at follow ups

complication rates of angioplasty alone and angioplasty with stenting or between self-expandable and balloon expandable stents. Current literature suggests higher complications in iliac stenting (4\% - 19\%) (20-22) compared to angioplasty alone $(3 \%-7.9 \%)(23,24)$. In a study by Benetis et al. in 2016, on the results of endovascular stenting between TASC II subtypes, the overall complication was reported to be $7.4 \%$ (25). Also Suzuki et al. showed that in a group of 2601 aortoiliac diseases, the complications are significantly higher in TASC D than cumulative complication in TASC A, B and C (11.1\% vs. 5.2\%, P < 0.01) (26). Kudo et al. (15) and Grimme et al. (27) both proposed that there are no differences between bare metal and covered stents in terms of complications.

Primary patency was defined as a treated vessel that remained open without restenosis or needed to be revascularized. If a stenotic target lesion undergoes redo revascularization to improve patency, it is known as assisted primary patency and if an occluded target lesion reopens repeatedly by revascularization it is called secondary patency (13). In our study, the Kaplan-Meier analysis estimated primary patency rate of TASC subtypes A - D at 1 year as $96.3 \%$, $100 \%, 66.7 \%$, and $96.3 \%$, respectively. Two-year primary patency rates were $96.3 \%, 100 \%, 66.7 \%$, and $81.6 \%$ for A - D TASC subtypes, respectively. Traditionally TASC C and D lesion were known to be treated successfully with open surgery, but there were reports about high primary patency rate (ranging $72 \%-89 \%$ ) even in these patients after endovascular treatment $(28,29)$. Grimme et al. investigated primary patency rates in patients with TASC C/ D aortoiliac lesions treated with either endovascular or surgery treatment and reported that the primary patency rates at 1 and 2 years were $83 \%$ and $79.9 \%$ after endovascular stenting and $97.1 \%$ and $97.1 \%$ after surgical approach (27). In a study by Taurino et al., the primary patency rate was 93.3\%, 90.2\%, and $86.6 \%$ at 1,2 , and 3 years, respectively (19). Also Grimme et al. revealed that 1-year primary patency of bare metal stents rates between $76 \%$ and $100 \%$ and a 5 -year primary patency rate is in a range of $63 \%$ to $83 \%$. In their study, one-year primary patency of covered stents reported to be between $70 \%$ and $100 \%$, but they were unable to report long-term primary patency rate for covered stents. Although we reported a higher primary patency rate for TASC D compared to TASC C patients, it seems to be due to the lower number of TASC C patients. This finding does not conflict our results about other TASC subtypes. It just emphasizes on performing future studies with equal cases in subgroups for proper intra group comparisons.

There are few limitations to our study that should be considered and resolved in future researches. First, we recruited patients from a single hospital that might induce selection bias. Second, although we managed to investigate 58 patients in our study, studies with larger sample sizes are recommended to confirm obtained results. The number of patients in TASC subtype B and C are too small that prevented us from inter-subtypes analysis. Third, we followed patients in specific time intervals, but it was not completely matched to the time of occurring stenosis in patients. Thus, it might have compromised the diagnosis of primary patency rate.

In conclusion, it is important to categorize patients based on TASC II morphological stratification after the initial diagnosis of aortoiliac occlusive disease. In this manner, not only patients would receive proper treatment with minimum complications, they would be aware of their prognosis. Our study is suggestive that percutaneous transluminal angioplasty is a feasible and safe procedure providing considerable technical success and primary patency rate in each subtype of TASC II for aortoiliac occlusive disease.

\section{Acknowledgments}

Authors would like to thank research development center of Sina hospital and primary prevention of cardiovascular disease research center for their kind contributions in every step of performing this study. 


\section{Footnotes}

Authors' Contributions: Study concept and design, Mohammad Hassani, Mohammad Reza Zafarghandi, and Morteza Taghavi; acquisition of data; Javad Salimi, and Majid Moini; analysis and interpretation of data, Mohammad Hassani, Amirsina Sharifi, and Soheil Saadat; drafting of the manuscript, Amirsina Sharifi, Morteza Noaparast, and Mohammad Reza Toubaei; critical revision of the manuscript for important intellectual content, Morteza Shahbandari, and Somayeh Alsadat Naserinia; statistical analysis, Amirsina Sharifi, and Soheil Saadat; administrative, technical, and material support, Mohammad Hassani, Mohammad Reza Zafarghandi, and Farzad Biniaz; study supervision, Mohammad Hassani, and Mohammad Reza Zafarghandi.

Financial Disclosure: This study was conducted using no special grant or funding.

Implication: Primary patency rate and technical success rate are two important factors in times of choosing best treatment for patients with aortoiliac occlusive disease. We showed that patients with different TASC II morphological stratification can be properly managed with endovascular treatment with considerable technical success rate and primary patency rate.

Funding/Support: This study was conducted using no special grant or funding.

\section{References}

1. Kakkos SK, Haurani MJ, Shepard AD, Nypaver TJ, Reddy DJ, Weaver MR, et al. Patterns and outcomes of aortofemoral bypass grafting in the era of endovascular interventions. Eur J Vasc Endovasc Surg. 2011;42(5):658-66. doi: 10.1016/j.ejvs.2011.07.010. [PubMed: 21865062].

2. Kavaliauskiene Z, Antusevas A, Kaupas RS, Aleksynas N. Recent advances in endovascular treatment of aortoiliac occlusive disease. Medicina (Kaunas). 2012;48(12):653-9. [PubMed: 23652624].

3. Ratnam L, Raza SA, Horton A, Taylor J, Markose G, Munneke G, et al. Outcome of aortoiliac, femoropopliteal and infrapopliteal endovascular interventions in lesions categorised by TASC classification. Clin Radiol.2012;67(10):949-54.doi:10.1016/j.crad.2011.12.011.[PubMed: 22947210].

4. Black J3, LaMuraglia GM, Kwolek CJ, Brewster DC, Watkins MT, Cambria RP. Contemporary results of angioplasty-based infrainguinal percutaneous interventions. J Vasc Surg. 2005;42(5):932-9. doi: 10.1016/j.jvs.2005.06.024. [PubMed:16275450].

5. Schillinger M, Diehm N, Baumgartner I, Minar E. TASC II section $\mathrm{F}$ on revascularization: commentary from an interventionist's point of view. J Endovasc Ther. 2007;14(5):734-42. doi: 10.1177/152660280701400519. [PubMed: 17924741].

6. Norgren L, Hiatt WR, Dormandy JA, Nehler MR, Harris KA, Fowkes FG, et al. Inter-Society Consensus for the Management of Peripheral Arterial Disease (TASC II). Eur J Vasc Endovasc Surg. 2007;33 Suppl 1:S1-75. doi: 10.1016/j.ejvs.2006.09.024. [PubMed: 17140820].

7. Uher $\mathrm{P}$, Nyman $\mathrm{U}$, Lindh $\mathrm{M}$, Lindblad $\mathrm{B}$, Ivancev $\mathrm{K}$. Long-term results of stenting for chronic iliac artery occlusion. J Endovasc Ther. 2002;9(1):67-75. doi: 10.1177/152660280200900112. [PubMed 11958328].
8. Blair JM, Gewertz BL, Moosa H, Lu CT, Zarins CK. Percutaneous transluminal angioplasty versus surgery for limb-threatening ischemia. J Vasc Surg. 1989;9(5):698-703. doi: 10.1067/mva.1989.vs0090698. [PubMed: 2524606].

9. London NJ, Varty K, Sayers RD, Thompson MM, Bell PR, Bolia A. Percutaneous transluminal angioplasty for lower-limb critical ischaemia. Br J Surg. 1995;82(9):1232-5. doi: 10.1002/bjs.1800820925. [PubMed: 7552004].

10. Ichihashi S, Higashiura W, Itoh H, Sakaguchi S, Nishimine K Kichikawa K. Long-term outcomes for systematic primary stent placement in complex iliac artery occlusive disease classified according to Trans-Atlantic Inter-Society Consensus (TASC)-II. J Vasc Surg. 2011;53(4):992-9. doi: 10.1016/j.jvs.2010.10.069. [PubMed: 21215582].

11. Maurel B, Lancelevee J, Jacobi D, Bleuet F, Martinez R, Lermusiaux P. Endovascular treatment of external iliac artery stenoses for claudication with systematic stenting. Ann Vasc Surg. 2009;23(6):722-8. doi: 10.1016/j.avsg.2008.05.019. [PubMed:19748218].

12. Hans SS, DeSantis D, Siddiqui R, Khoury M. Results of endovascular therapy and aortobifemoral grafting for Transatlantic Inter-Society type C and D aortoiliac occlusive disease. Surgery. 2008;144(4):5839. discussion 589-90. doi: 10.1016/j.surg.2008.06.021. [PubMed: 18847642]

13. Rutherford RB, Baker JD, Ernst C, Johnston KW, Porter JM, Ahn S, et al. Recommended standards for reports dealing with lower extremity ischemia: revised version. J Vasc Surg. 1997;26(3):517-38. doi: 10.1016/S0741-5214(97)70045-4. [PubMed: 9308598].

14. Humphries MD, Armstrong E, Laird J, Paz J, Pevec W. Outcomes of covered versus bare-metal balloon-expandable stents for aortoiliac occlusive disease. J Vasc Surg. 2014;60(2):337-43. doi: 10.1016/j.jvs.2014.02.055. [PubMed: 24725909].

15. Kudo T, Chandra FA, Ahn SS. Long-term outcomes and predictors of iliac angioplasty with selective stenting. J Vasc Surg. 2005;42(3):46675. doi: 10.1016/j.jvs.2005.05.002. [PubMed:16171589].

16. Uberoi R, Milburn S, Moss J, Gaines P, Bias Registry Contributors British Society of Interventional Radiology Iliac Artery AngioplastyStent Registry III. Cardiovasc Intervent Radiol. 2009;32(5):887-95. doi: 10.1007/s00270-009-9634-3. [PubMed: 19644643].

17. Lun Y, Zhang J, Wu X, Gang Q, Shen S, Jiang H, et al. Comparison of midterm outcomes between surgical treatment and endovascular reconstruction for chronic infrarenal aortoiliac occlusion. J Vasc Interv Radiol.2015;26(2):196-204.doi:10.1016/j.jvir.2014.10.018. [PubMed: 25529189].

18. Tewksbury R, Taumoepeau L, Cartmill A, Butcher A, Cohen T. Outcomes of covered expandable stents for the treatment of TASC D aorto-iliac occlusive lesions. Vascular. 2015;23(6):630-6. doi: 10.1177/1708538114568479. [PubMed: 25819513].

19. Taurino M, Persiani F, Fantozzi C, Ficarelli R, Rizzo L, Stella N. TransAtlantic Inter-Society Consensus II C and D iliac lesions can be treated by endovascular and hybrid approach: a single-center experience. Vasc Endovascular Surg. 2014;48(2):123-8. doi: 10.1177/1538574413512381. [PubMed: 24270686].

20. Ballard JL, Sparks SR, Taylor FC, Bergan JJ, Smith DC, Bunt TJ, et al. Complications of iliac artery stent deployment.JVasc Surg.1996;24(4):54553. discussion 553-5. doi: 10.1016/S0741-5214(96)70070-8. [PubMed: 8911403].

21. Ballard JL, Bunt TJ, Malone JM. Major complications of angioaccess surgery. Am J Surg. 1992;164(3):229-32. doi: 10.1016/S00029610(05)81076-1. [PubMed: 1415920].

22. Treiman GS, Schneider PA, Lawrence PF, Pevec WC, Bush RL, Ichikawa L. Does stent placement improve the results of ineffective or complicated iliac artery angioplasty? JVasc Surg.1998;28(1):104-12. discussion 113-4. [PubMed: 9685136].

23. Johnston KW. Iliac arteries: reanalysis of results of balloon angioplasty. Radiology. 1993;186(1):207-12. doi: 10.1148/radiology.186.1.8416566. [PubMed: 8416566]. 
24. Gardiner GJ, Meyerovitz MF, Stokes KR, Clouse ME, Harrington DP Bettmann MA. Complications of transluminal angioplasty. Radiol ogy. 1986;159(1):201-8. doi: 10.1148/radiology.159.1.2937082. [PubMed: 2937082].

25. Benetis R, Kavaliauskiene Z, Antusevas A, Kaupas RS, Inciura D, Kinduris S. Comparison of results of endovascular stenting and bypass grafting for TransAtlantic Inter-Society (TASC II) type B, C and D iliac occlusive disease. Arch Med Sci. 2016;12(2):353-9. doi 10.5114/aoms.2016.59261. [PubMed: 27186180].

26. Suzuki K, Mizutani Y, Soga Y, Iida O, Kawasaki D, Yamauchi Y, et al. Efficacy and Safety of Endovascular Therapy for Aortoiliac TASC D Lesions. Angiology. 2017;68(1):67-73. doi: 10.1177/0003319716638005. [PubMed: 26980775].
27. Grimme FA, Goverde PA, Van Oostayen JA, Zeebregts CJ, Reijnen MM. Covered stents for aortoiliac reconstruction of chronic occlusive lesions. J Cardiovasc Surg (Torino). 2012;53(3):279-89. [PubMed: 22695260].

28. AbuRahma AF, Hayes JD, Flaherty SK, Peery W. Primary iliac stenting versus transluminal angioplasty with selective stenting. J Vasc Surg. 2007;46(5):965-70. doi:10.1016/j.jvs.2007.07.027. [PubMed:17905559].

29. Leville CD, Kashyap VS, Clair DG, Bena JF, Lyden SP, Greenberg RK, et al. Endovascular management of iliac artery occlusions: extending treatment to TransAtlantic Inter-Society Consensus class $C$ and D patients. J Vasc Surg. 2006;43(1):32-9. doi: 10.1016/j.jvs.2005.09.034. [PubMed: 16414384]. 